\title{
Design and Implementation of a New PWM Based Active Impedance Power Factor Correction (AIPFC)
}

\author{
S. Ali Al-Mawsawi \\ Department of Electrical and Electronics Engineering, College of Engineering, \\ University of Bahrain, P. O. Box 32038, Kingdom of Bahrain
}

\begin{abstract}
In this paper a new circuit for improving the input power factor is proposed. The proposed circuit is constructed based on active elements and it is called Active Impedance Power Factor Correction (AIPFC). The operation of the AIPFC is based on a PWM technique and it will be modeled and tested using a MATLAB Program (SIMULINK). In this case, the AIPFC model is installed in two different power electronics applications. The simulation results for both applications will be presented and compared with the circuit that the AIPFC is not installed. In both applications the Input Power Factor $\left(P F_{i n}\right)$ and the Total Harmonic Distortion $(T H D)$ will be recorded. In addition, the proposed AIPFC is implemented and tested and the experimental result will be presented.
\end{abstract}

\section{KEYWORDS}

POWER FACTOR CORRECTION (PFC), PWM BASED INVERTER, TOTAL HARMONIC DISTORTION (THD).

\section{INTRODUCTION}

Every year, millions and millions of notebook computers, LCD monitors and LCD televisions are produced. With such a fast growing number of these and other electronic devices using more and more power, actions must to be taken to ensure the functionality of the nationwide power grid ${ }^{[1-4]}$. In 2001, the European Union put EN61000-3-2 into effect to set the harmonic regulation standard on any power grid supplied application with power consumption over 75 watts. This essentially requires power factor correction (PFC). Therefore, power factor improvement is the growing issue of concern. Within power quality framework, one of the important aspects is reactive power control. Consumer load requires reactive power that varies incessantly and increases transmission losses while affecting voltage in the transmission network. To prevent unacceptably high voltage fluctuations or the power failures that can result, this reactive power must be compensated and kept in balance. This function has always been performed by passive elements such as reactors or capacitor, as well as combination of the two that supply inductive or capacitive reactive power. The more quickly and precisely the reactive power can be compensated, the more efficiently the various characteristics of transmissions can be controlled. Since most loads in modern electrical distribution systems are inductive, there is an ongoing interest in improving power factor. The low power factor of inductive loads robs a system of capacity and can adversely affect voltage level. As such, power factor correction through the application of capacitors, Synchronous Alternators, TCR, SVC, Power Electronic DC-DC convertors etc. is widely practiced at all system voltages. As utilities increase penalties they charge customers for low power factor, 
system performance will not be the only consideration. The installation of power factor correction circuits improves system performance and saves money. In order to ensure most favorable condition for a supply system from engineering and economic standpoint it is important to have power factor as close to unity as possible. Linear loads with low power factor (such as induction motors) can be corrected with a passive network of capacitors or inductors. Non-linear loads, such as rectifiers, distort the current drawn from the system. In such cases, active or passive power factor correction may be used to counteract the distortion and raise power factor. The devices for correction of power factor may be at a central substation, or spread out over a distribution system, or built into power-consuming equipment ${ }^{[5-23]}$. In this paper, a new PWM based active impedance power factor correction (AIPFC) will be designed and implemented for such non-linear loads.

\section{Principle OPERATION OF AN ACTIVE IMPEDANCE POWER FACTOR CORRECTION (AIPFC)}

The principle operation of the proposed AIPFC is to generate an injecting voltage in the circuit with the phase shift of 90 degree lagging with the line current in order to get effect of capacitive impedance.

Power electronic offer a solution to supply a voltage has different phase with current in a way to give the effect of the impedance in an active way without using passive components. In addition this reduce much problem such as using a capacitor to improve power factor that cause a sub-synchronous resonance that lead to broke shaft in generators.

Figure 1 shows the block diagram of the AIPFC connected between node a and node b. It contains of five boxes that represent system to make the desired effect of the variable capacitive impedance.

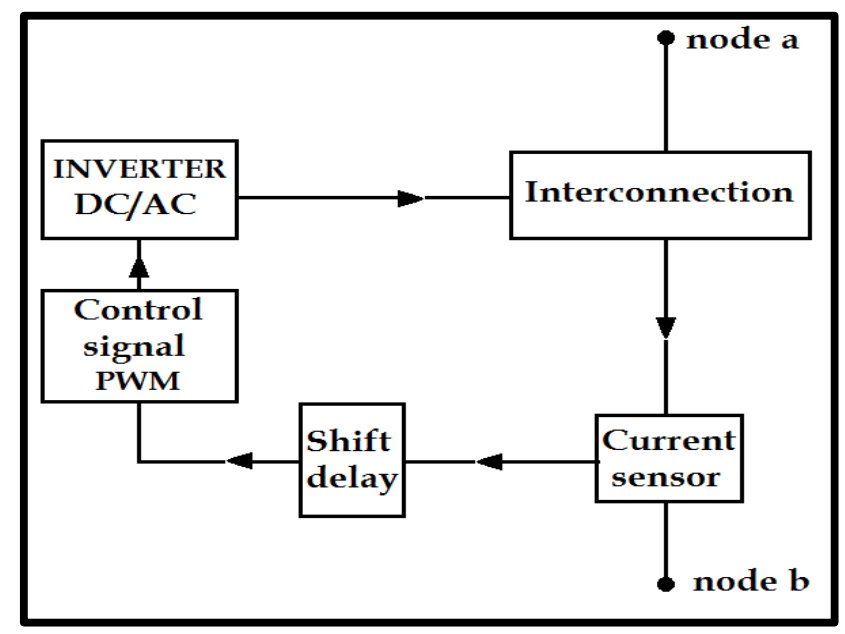

Figure 1: Block diagram of the AIPFC.

The operation of the system is starting with a current sensor to measure the zero crossing time of the current in the branch a-b and then to determine reference waveform. In this part either a current transformer can be used to measure the current in the branch a-b or a resistor with a value of $1 \Omega$ can be used to measure the voltage across it (it will be the same as a current waveform according to the ohm's law). The output signal from the current sensor circuit is then passed to the shift delay circuit box. A shift delay circuit is the main part of the system 
that is used to determine the type of the impedance to be produced in that process. In this case, the output waveform from the shift delay circuit can produce the effect of three types of impedances and it will be as following:

a) 0 degree of phase shift will produce an effect of a resistive load.

b) +90 degree of phase shift will produce an effect of a capacitive load.

c) -90 degree of phase shift will produce an effect of an inductive load.

The output signal from the phase shift delay circuit is then compared with a triangular waveform to generate PWM gate signals for the inverter circuit. Finally, the output signal is injected to the main system by using a shunt transformer as shown in the circuit diagram of figure 2. Therefore, the injected voltage signal can have the effect of any type of the impedance (resistive, inductive or capacitive) in the circuit. In addition, the magnitude of the effected impedance can be varied or controlled by varying the modulation index of the PWM waveform.

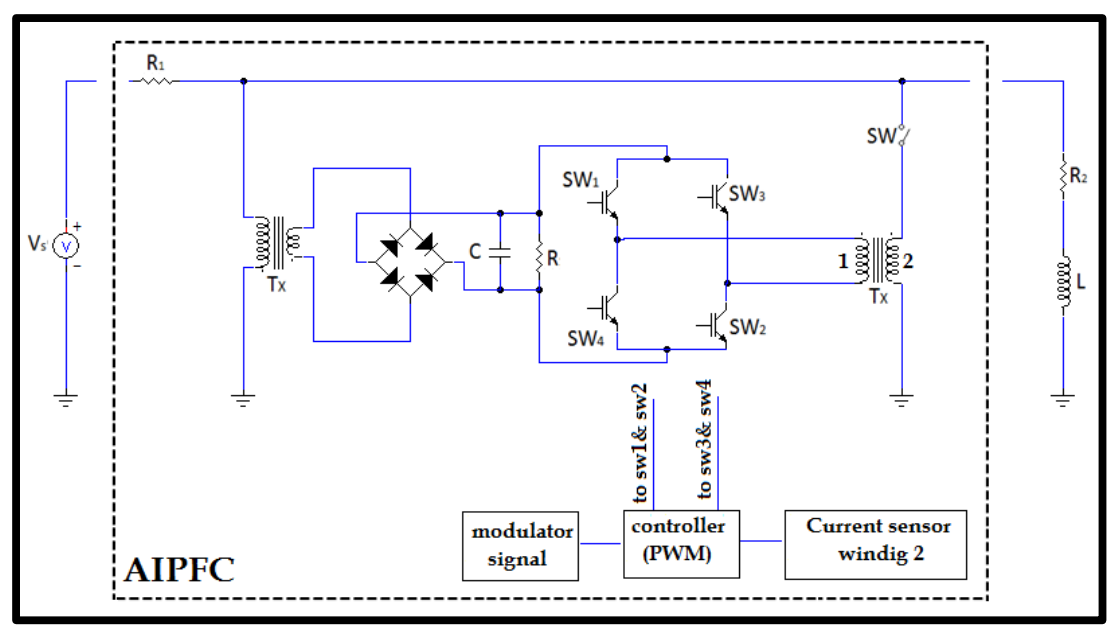

Figure 2: AIPFC circuit diagram.

\section{SimULATION RESULTS}

The above proposed AIPFC circuit was tested and simulated using SIMULINK program in the following power electronics applications:

\subsection{A Single Phase Phase-Angle Control with Resistive Load}

Figure 3 shows a single phase phase-angle control with resistive load and AIPFC. In this case the input power factor without AIPFC can be calculated as following ${ }^{[24]}$ :

$$
P F_{\text {in }}=\sqrt{\left[\frac{(\pi-\alpha)+0.5 \sin 2 \alpha}{2 \pi}\right]}
$$

Where, $\alpha$ is called the firing angle of the Triac.

In addition, the total harmonic distortion (THD) can be calculated as following ${ }^{[24]}$ :

$\mathrm{THD}=\frac{1}{V_{o 1}} \sqrt{\sum_{n=2,3, \ldots}^{\infty}\left(\mathrm{V}_{\mathrm{n}}^{2}\right)}$ 
Table 1 shows the comparison simulation results for the circuit given in figure 3 with and without AIPEC and in case of modulation index (M) equals to 60\%. It can be seen that, for each extreme value of the firing angle $(\alpha)$ the Input Power Factor $\left(\mathrm{PF}_{\text {in }}\right)$ has been improved. In addition, the Total Harmonic Distortion (THD) has been also improved at each extreme value of the firing angle $(\alpha)$. Figure 4 represents the simulation results for the circuit given in figure 3 with and without AIPEC and in case of modulation index (M) is varying. It can be seen that for all values of modulation index $(\mathrm{M})$ the Input Power Factor $\left(\mathrm{PF}_{\text {in }}\right)$ has been improved at each extreme value of firing angle $(\alpha)$. Moreover, the Input Power Factor $\left(\mathrm{PF}_{\text {in }}\right)$ is also increases as the modulation index $(\mathrm{M})$ is increasing.

Table 1: Simulation results for the circuit given in figure 3.

\begin{tabular}{|c|c|c|c|c|}
\hline \multicolumn{5}{|c|}{$V s=240 V, R=50 \Omega, M=60 \%$} \\
\hline $\begin{array}{c}\text { Firing Angle } \\
(\alpha)\end{array}$ & $\begin{array}{c}\text { PF }_{\text {in without }} \\
\text { AIPEC }\end{array}$ & $\begin{array}{c}\text { PF }_{\text {in with }} \\
\text { AIPEC }\end{array}$ & $\begin{array}{c}\text { THD Without } \\
\text { AIPEC }\end{array}$ & $\begin{array}{l}\text { THD With } \\
\text { AIPEC }\end{array}$ \\
\hline $60^{\circ}$ & 0.9603 & 0.9856 & $37.83 \%$ & $33.9 \%$ \\
\hline $90^{\circ}$ & 0.8427 & 0.933 & $66.62 \%$ & $58.9 \%$ \\
\hline $120^{\circ}$ & 0.6375 & 0.890 & $96.30 \%$ & $93.00 \%$ \\
\hline
\end{tabular}

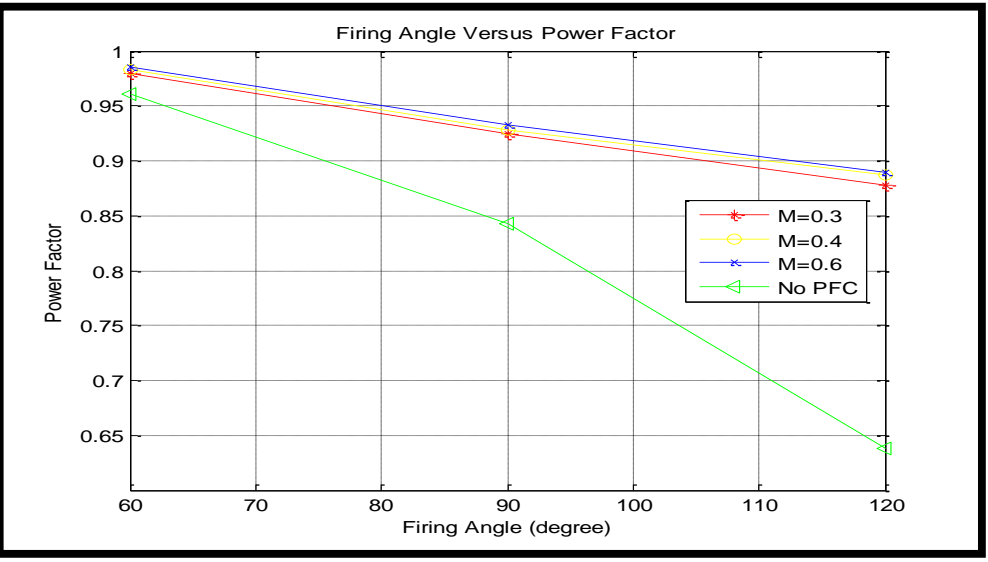

Figure 3: A single phase phase-angle control with resistive load and AIPFC. 


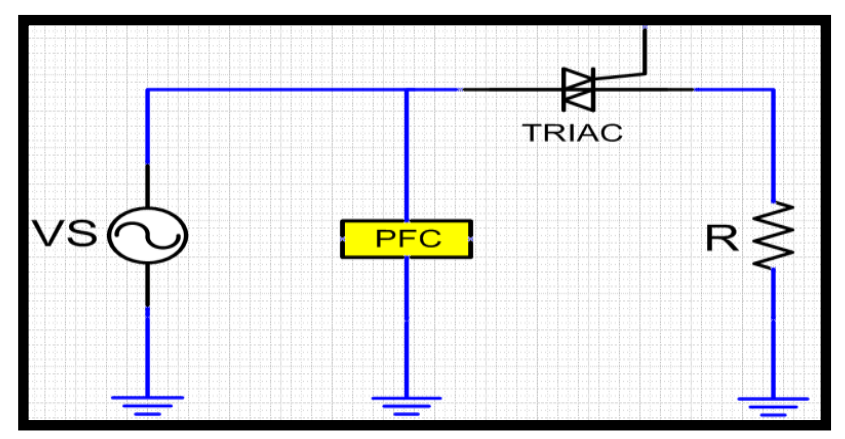

Figure 4: Simulation results for the circuit given in figure 3.

\subsection{A Single Phase Phase-Angle Control with RL Load}

Figure 5 shows a single phase phase-angle control with RL load and AIPFC. In this case the input power factor without AIPFC can be calculated as following ${ }^{[24]}$ :

$$
P F_{\text {in }}=\cos \emptyset\left[\frac{\delta}{\pi}-\frac{\sin \delta}{\pi \cos \varnothing} \cos (2 \alpha+\delta+\emptyset)\right]^{0.5}
$$

Where, $\delta$ is the conduction angle of the Triac and $\phi$ is the load angle.

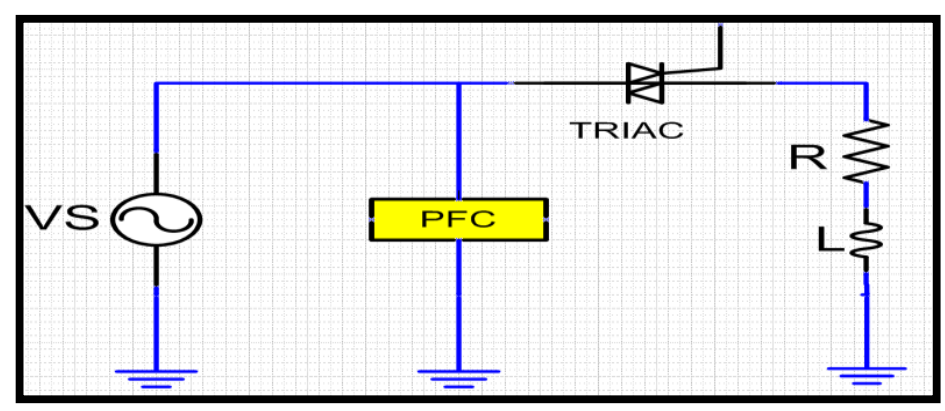

Figure 5: A single phase phase-angle control with RL load and AIPFC.

It can be seen from Table 2 and Figure 6 that the same results have been recorded when the load was resistive in terms of improving the Input Power Factor $\left(\mathrm{PF}_{\mathrm{in}}\right)$ and the Total Harmonic Distortion (THD). Therefore, more improvement can be recorded if the modulation index $(\mathrm{M})$ is increased and this is because the percentage of the capacitive compensation will be increased. 
International Journal of Microelectronics Engineering (IJME), Vol.2, No.1,January 2016

Table 2: Simulation results for the circuit given in figure 5.

\begin{tabular}{|c|c|c|c|c|}
\hline \multicolumn{5}{|c|}{$V s=240 \mathrm{~V}, \mathrm{R}=50 \Omega, L=0.1 \mathrm{H}, \mathrm{M}=60 \%$} \\
\hline $\begin{array}{l}\text { Firing Angle } \\
(\alpha)\end{array}$ & $\begin{array}{c}\text { PF }_{\text {in without }} \\
\text { AIPEC }\end{array}$ & $\begin{array}{c}\text { PF }_{\text {in with }} \\
\text { AIPEC }\end{array}$ & $\begin{array}{l}\text { THD Without } \\
\text { AIPEC }\end{array}$ & $\begin{array}{l}\text { THD With } \\
\text { AIPEC }\end{array}$ \\
\hline $30^{\circ}$ & 0.847 & 0.941 & $2.96 \%$ & $0.20 \%$ \\
\hline $60^{\circ}$ & 0.741 & 0.897 & $16.55 \%$ & $14.58 \%$ \\
\hline $90^{\circ}$ & 0.562 & 0.855 & $38.25 \%$ & $34.00 \%$ \\
\hline
\end{tabular}

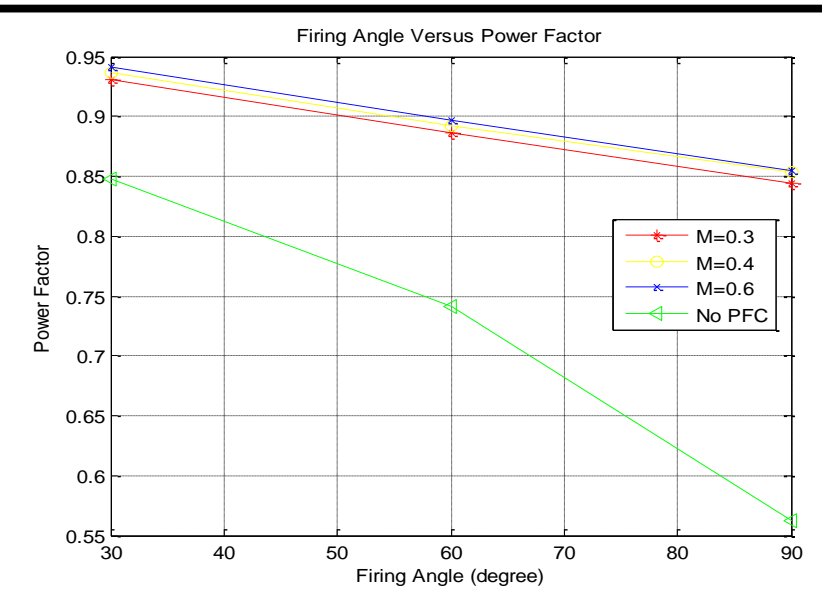

Figure 6: Simulation results for the circuit given in figure 5.

\section{IMPLEMENTATION OF AIPFC}

Figure 7 represents the experimental circuit which consists of a voltage source feeding RL load with Active Impedance Power Factor Correction (AIPFC). Practically, the AIPFC consists of an Integrated Circuit, Microcontroller (PIC16F877A), Interfacing Circuit, and a Voltage Source Inverter (VSI). The operation of this figure will as following:

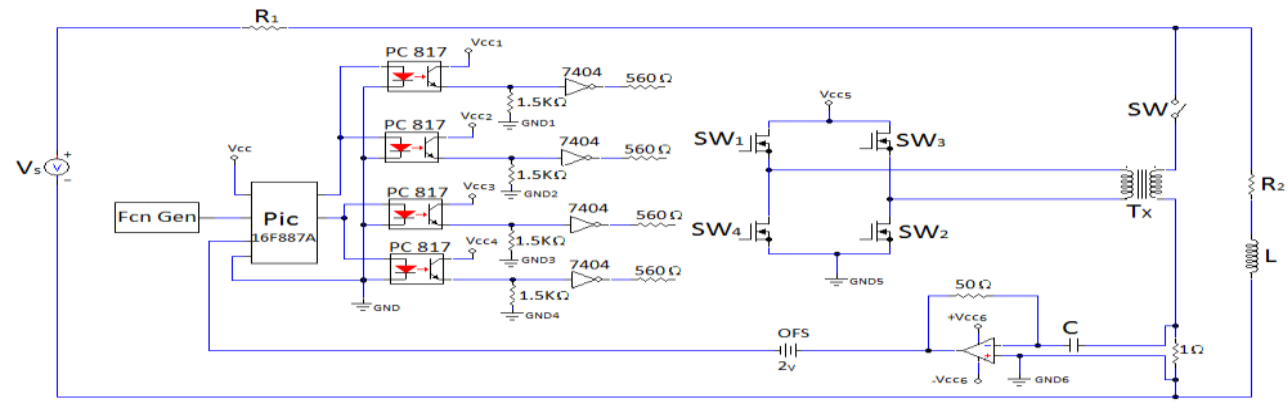

Figure 7: Experimental c ircuit with AIPFC. 


\subsection{Integrated Circuit}

It is used to sense the current waveform from the branch at which the AIPFC is connected. This current waveform is then integrated (shifted be $90^{\circ}$ ) and connected to the input of the Microcontroller (PIC16F877A). Figure 8(a) shows the integrated circuit and figure 8(b) shows the input and output waveforms of the integrator circuit.

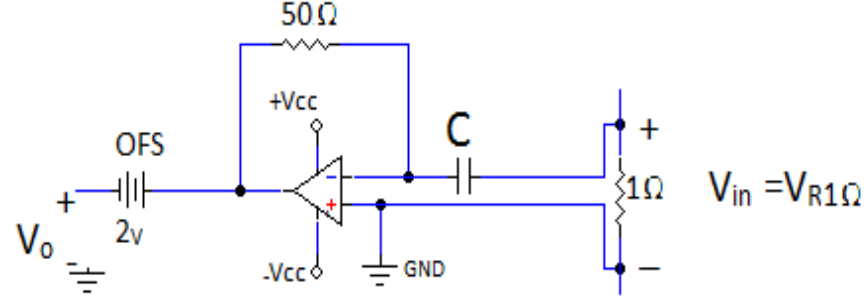

(a)

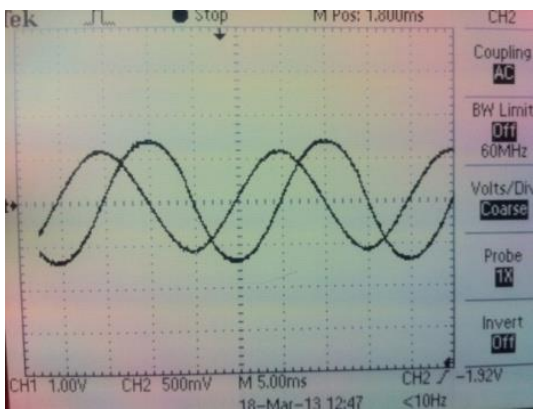

(b)

Figure 8: (a) Integrated circuit, (b) Input and output waveforms of the integrator circuit.

\subsection{Microcontroller (PIC16F877A)}

A microcontroller PIC16F877A chip shown in figure 9(a) has been used to generate gate signals for the inverter switches. In this case, a program written and loaded to the microcontroller in order to read the input signals from its port A and generates output signals at its ports $\mathrm{B}$ and $\mathrm{C}$. The main function of this program is to compare between the two input signals (a triangular wave and output signal from the integrated circuit) and to generate two PWM signals at the output ports (B and C) of the microcontroller as shown in figure 9(b). In addition, the dead time between the two outputs signals generated by the microcontroller is also included in the program as shown in figure 10.

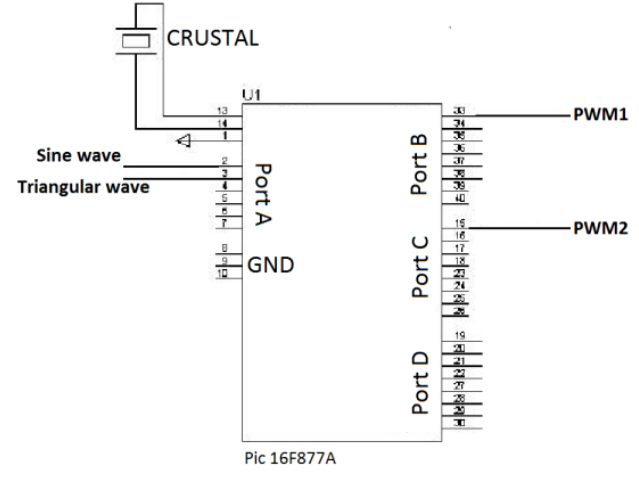

(a)

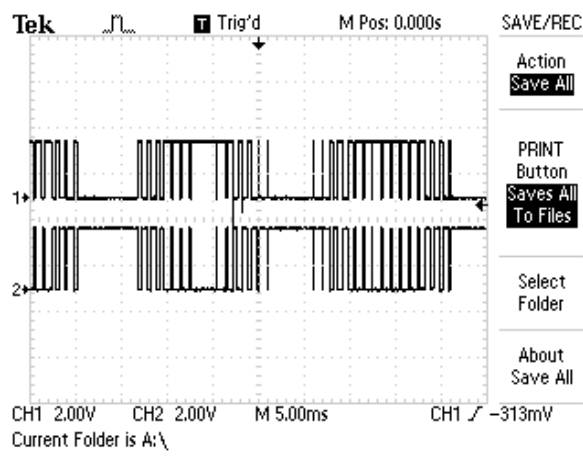

(b)

Figure 9: (a) A microcontroller PIC16F877A chip, (b) Output waveforms from Ports B and C. 


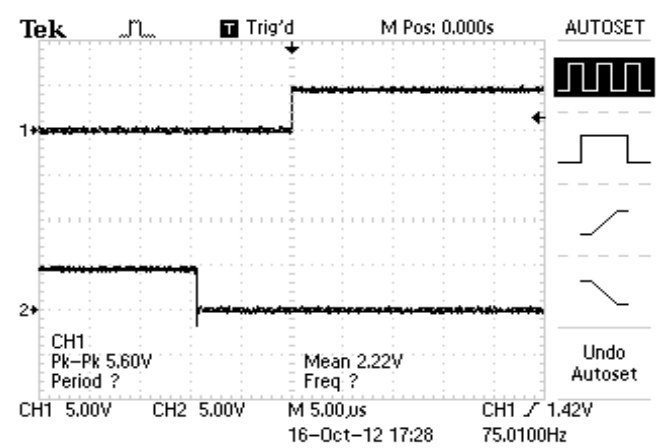

Figure 10: The dead time between the two outputs signals at ports B and C.

\subsection{Interfacing Circuit}

The interfacing circuit is used to interface the signal output from the microcontroller to the power electronics circuit (inverter). This circuit consists of two sections as shown in figure 11 .

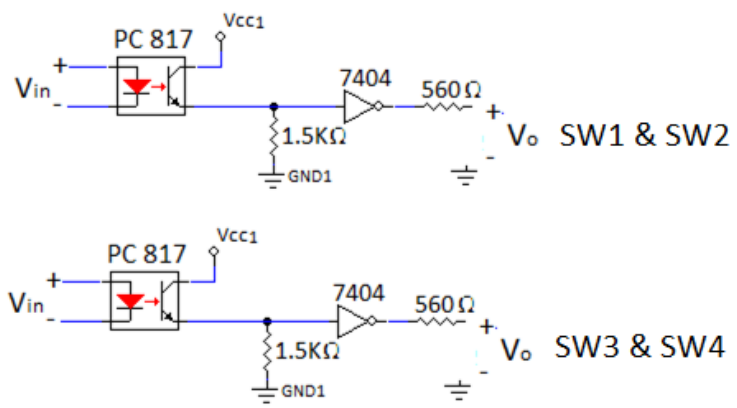

Figure 11: Interfacing Circuit

\subsubsection{Opto-coupler Circuit}

This circuit consists of four sets of Opto-coupler PC817. They are used to isolate the microcontroller output signals from the power electronics circuit.

\subsubsection{Inverter Buffer Circuit}

The second section contains the inverter buffers (IC7404) which are used to invert and boost the Opto-coupler output voltages from $5 \mathrm{~V}$ to $15 \mathrm{~V}$.

\subsection{Voltage Source Inverter with Its Driver Circuit}

This section consists of two sets of the International Rectifier's IR2110 gate drivers. Each of these drivers is used to drive one high side and one low side of one leg of the single phase inverter. With additional components (as shown in figure 12), the IR2110 provides very fast switching speeds (approximately $35 \mathrm{~ns}$ for the rise time and $25 \mathrm{~ns}$ for the fall time) and low power dissipation. These drivers are operated on the bootstrap principle to handle a high switching frequency $(3.2 \mathrm{kHz})$ at the IGBTs gates. Figure 13 shows the inverter output voltage waveform. 


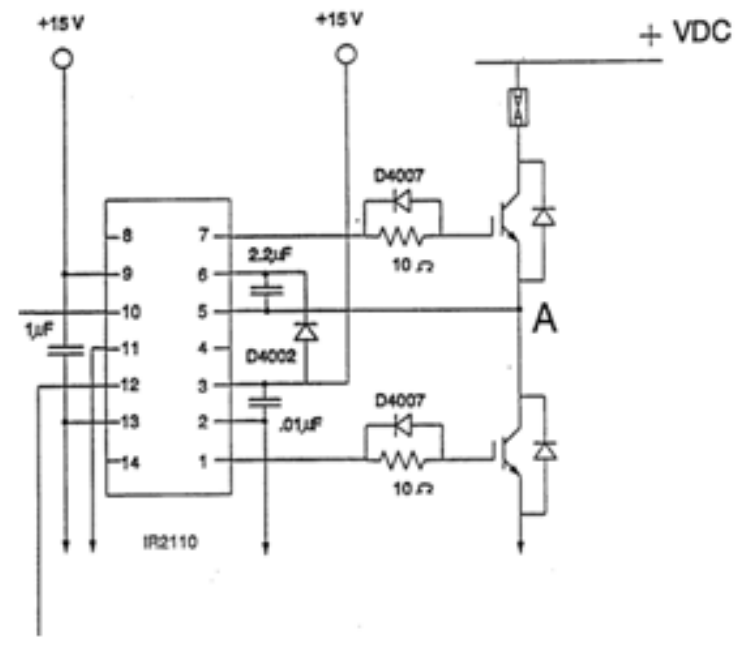

Figure 12: Voltage source inverter with its driver circuit.

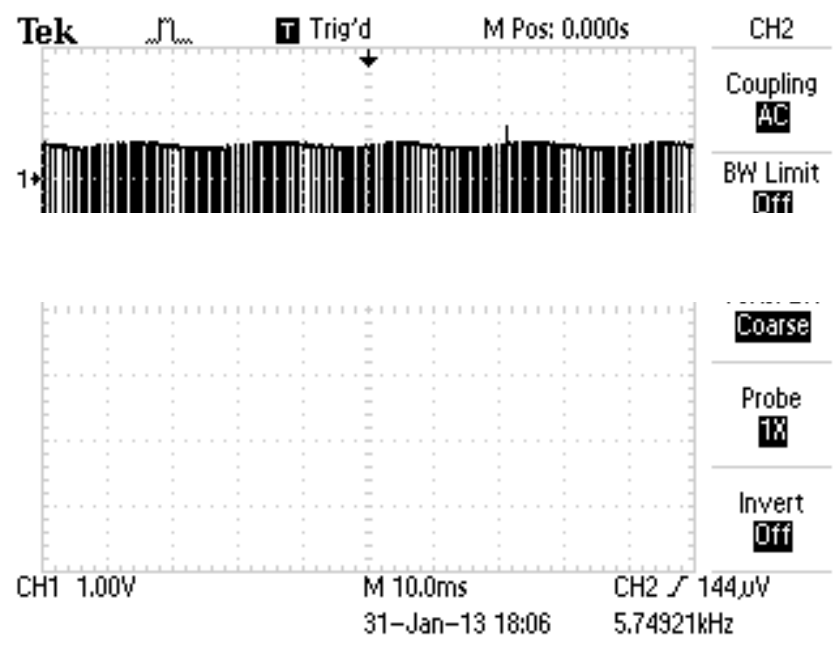

Figure 13: Inverter output voltage waveform.

\subsection{Experimental Results}

Table 3 shows the comparison experimental results for the circuit given in figure 7 with and without AIPEC and in case of modulation index (M) equals to 60\%. It can be seen that, for each extreme value of the load inductance value, the Input Power Factor $\left(\mathrm{PF}_{\text {in }}\right)$ has been improved. 
Table 3: Experimental results for the circuit given in figure 7.

\begin{tabular}{|c|c|c|}
\hline \multicolumn{3}{|c|}{$V s=240 \mathrm{~V}, \mathrm{R}=50 \Omega, \mathrm{M}=60 \%$} \\
\hline $\mathbf{L}(\mathbf{H})$ & $\begin{array}{c}\text { PF }_{\text {in without }} \\
\text { AIPEC }\end{array}$ & $\begin{array}{c}\text { PF }_{\text {in with }} \\
\text { AIPEC }\end{array}$ \\
\hline 0.1 & 0.8467 & 0.928 \\
\hline 0.5 & 0.303 & 0.652 \\
\hline 1.0 & 0.157 & 0.488 \\
\hline
\end{tabular}

\section{CONCLUSiOnS}

A new circuit for improving the input power factor has been proposed. The proposed circuit is constructed based on active elements and it is called Active Impedance Power Factor Correction (AIPFC). The operation of the AIPFC is based on a PWM technique and it has been modeled and tested using a MATLAB Program (SIMULINK). In this case, the AIPFC model has been installed in two different power electronics applications. The first application is a single phase phase-anlge controlled with resistive load. The input power factor in this application is depending on the firing angle only and it has been shown that with installing AIPFC both $\mathrm{PF}_{\text {in }}$ and THD have been improved at any firing angle. While the second application is a single phase phase-anlge controlled with RL load. However, the input power factor in this application is depending on both the firing angle and the load angle. It has been shown that with installing AIPFC both $\mathrm{PF}_{\text {in }}$ and $\mathrm{THD}$ have been also improved. In both applications more improvement of both $\mathrm{PF}_{\text {in }}$ and THD can be achieved by increasing the compensation capacitive factor of AIPFC (modulation index of the inverter). In addition, the proposed AIPFC has been implemented and tested. The experimental results have been presented and they validate the simulation results.

\section{REFERENCES}

[1] Intel, "PC Energy-Efficiency Trends and Technologies (A closer look at energy consumption and emerging power-management technologies", USA, 2002, Pages 1-8.

[2] Dhaval Dalal, "Boosting Power Supplies Efficiency for Desktop Computers", Power Electronics Technology, February 2005, Pages 14-23.

[3] R. D. Middlebrook, "Predicting Modulator Phase Lag in PWM Converter Feedback Loops", POWERCON 8, pp. H4.1-H4.6, April 1981.

[4] B. Aebischer, "Towards Greater Energy Efficiency in the Use of Computers", UNEP Conference, London, 20-21 May 1996.

[5] M. Madigan, R. Erickson, and E. Ismail, "Integrated high-quality rectifier-regulators", in Proc. Conf. Rec. IEEE-PESC'92, pp. 1043-1051.

[6] P. Kornetzky, H. Wei, and I. Batarseh, "A novel one-stage power factor correction converter", in Proc. Conf. Rec. IEEE-APEC'97, pp. 251-258.

[7] R. Redl and L. Balogh, "Rms, Dc, Peak, and harmonic currents in highfrequency power-factor correctors with capacitive energy storage", in Proc. Conf. Rec. IEEE-APEC'92, pp. 533-540. 
[8] C. K. Duffey and R. P. Stratford, "Update of Harmonic Standard IEEE-519: IEEE Recommended Practices and Requirements for Harmonic Control in Electric Power Systems", IEEE Trans. on Industry Applications, vol. 25, no. 6, Nov. 1989, pp. 1025-1034.

[9] H. Akagi, "Trends in Active Power Line Conditioners", IEEE Trans. on Power Electronics, vol. 9, no. 3, May 1994, pp. 263-268.

[10] J. S. Lai,D. Hurst, and T. Key, "Switch-Mode Power Supply Power Factor Improvement Via Harmonic Elimination Methods", Conference Record of IEEE-APEC'91, pp. 415-422.

[11] M. O. Eissa, S. B. Leeb, G. C. Verghese, and A. M. Stankovic, "A Fast Analog Controller for a Unity-Power-Factor AC/DC Converter", Conference Record of APEC'94, pp. 551-555.

[12] Y. Jiang and F. C. Lee, "Single-Stage Single-Phase Parallel Power Factor Correction Scheme", Conference Record IEEE-PESC'94, pp. 1145-1151.

[13] A. R. Prasad, P. D. Ziogas, and S. Manias, "A New Active Power Factor Correction Method for Single-Phase Buck-Boost AC-DC Converter", Conference Record of IEEE-APEC'92, pp. 814820.

[14] J. C. Salmon, "Techniques for Minimizing the Input Current Distortion of Current-Controlled Single-Phase Boost Rectifiers", IEEE Trans. on Power Electronics, vol. 8, no. 4, Oct. 1993, pp. 509-520.

[15] R. Srinivasan and R. Oruganti, "A Unity Power Factor Converter Using Half-Bridge Boost Topology", IEEE Trans. on Power Electronics, vol. 13, no. 3, May 1998, pp. 487-500.

[16] M. Kazerani, P. D. Ziogas, and G. Joos, "A Novel Active Current Waveshaping Technique for Solid-State Input Power Factor Conditioners", IEEE Tans. on IE, vol. 38, no. 1, Feb. 1991, pp. 72-78.

[17] D. Maksimovic, Y. Jang, and R. Erickson, "Nonlinear-Carrier Control for High Power Factor Boost Rectifiers", Conference Record of APEC'95, pp. 635-641.

[18] A. Rao, and K. Ravikanth, "Analysis of Active Power Factor Correction Using Single and Dual Mode Boost Converter", International Journal of Electrical and Electronics Research ISSN 23486988 (online) Vol. 3, Issue 2, pp. 38-44 April-June 2015.

[19] Hiten Pahilwani, "Power Factor Correction Using Boost Converter", International Journal of Application or Innovation in Engineering \& Management (IJAIEM), Volume 4, Issue 8, August 2015.

[20] P. ArindamBiswas, S. Dhar, A.K. Basu, A. Ower "Factor Measurement and Correction using Digital Controller Implemented on FPGA", International Journal of Microelectronics Engineering (IJME), Vol. 1, No.1, 2015.

[21] S. Ali Al-Mawsawi, "Efficiency improvement of computer power supplies utilizing active power factor corrector", The International Journal for Electric Power Components and Systems, Volume 36, No. 12, December 2008.

[22] National Semiconductor, "Introduction to Power Supplies", Application Note 556, September 2002, Pages 1-7.

[23] Jon Mark Hancock, "Simplifying Power Factor Correction in SMPS", Power Electronics Technology, October 2004, Pages 26-38.

[24] M. Rashid, "Power Electronics (Circuits, Devices and Applications)", Third Edition, Prentice Hall, 2004. 